\title{
Three-Dimensional Reconstruction of Promastigote of Leishmania Amazonensis Treated With ACET-1 from Serial Sections Obtained by FIB-SEM
}

Rayanne R. B. Machado ${ }^{1 *}$, Deysiane L. Salvador ${ }^{2}$, Aline R. de Oliveira ${ }^{2}$, Maria Helena Sarragiotto ${ }^{2}$, Tania Ueda-Nakamura ${ }^{1}$, Sueli O. Silva ${ }^{1}$, Celso V. Nakamura ${ }^{1}$ and Danielle Lazarin-Bidóia ${ }^{1}$

1. Technological Innovation Laboratory in the Development of Pharmaceuticals and Cosmetics, Department of Basic Health Sciences, State University of Maringá, Maringá, Paraná, Brazil.

2. Department of Chemistry, State University of Maringá, Maringá, Paraná, Brazil.

* Corresponding author: raymachado6@hotmail.com

Leishmaniasis comprises a group of diseases that are caused by parasites the genus Leishmania, presented as a severe public health problem in many countries worldwide, affecting mainly regions that are socially and economically vulnerable ${ }^{[1]}$. The chemotherapeutic arsenal comprises just three main drugs (pentavalent antimonials, amphotericin B and miltefosine), which exhibit several limitations, including long administration regimens, hospitalization, high costs and severe adverse effects. The search for new drugs therefore remains a necessity, especially for developing countries ${ }^{[2]}$, however, in order to succeed in the development these new drugs, it is necessary to know all the structural and functional biology of the parasite, for the purpose of identify possible therapeutic targets. In this context, our research group has already shown in previous studies, that the synthetic compound 4-(5'-formyl-[2,2'-bithiophen]-5-yl)but-3-yn-1-yl acetate, ACET-1, induced ultrastructural and morphological changes in promastigotes of Leishmania amazonensis, when treated with $\mathrm{IC}_{50}(28.9$ $\mu \mathrm{M}$ ) for $72 \mathrm{~h}$. Based on this, we propose a strategy to increase the understanding of the mechanism of action of this compound, mainly on the cytoskeleton and plasma membrane of promastigote, and consequently the understanding of the ultrastructure of the parasite, using FIB-SEM techniques and producing a virtual $3 \mathrm{D}$ models. For this, promastigote $\left(1 \times 10^{6}\right.$ cells ml $\left.{ }^{-1}\right)$ were treated with $\mathrm{IC}_{50}$ of ACET-1 for $72 \mathrm{~h}$ at $28{ }^{\circ} \mathrm{C}$. After, the parasites were fixed in a solution of $2.5 \%$ glutaraldehyde in 0.1 $\mathrm{M}$ cacodylate buffer for $24 \mathrm{~h}$ at $4{ }^{\circ} \mathrm{C}$. Past this time, the parasites were post-fixed in a solution of $1 \%$ $\mathrm{OsO}_{4}, 0.8 \%$ potassium ferricyanide and $10 \mathrm{mM} \mathrm{CaCl}_{2}$ in $0.1 \mathrm{M}$ cacodylate buffer. The samples were dehydrated in increasing acetone gradient and embedded in Polybed 812 resin. Sputter-coated with gold was performed and the serial sections were obtained using the FIB-SEM double-beam microscope (FEI Scios). The alignment, segmentation and cell rendering was realized by AMIRA (FEI Company, USA). Our results demonstrated that ACET-1 induced morphological and ultrastructural alterations in promastigote at molecular level, destabilizing the protein bonds between the subpelicular microtubules and the plasma membrane resulting in morphological alterations. 


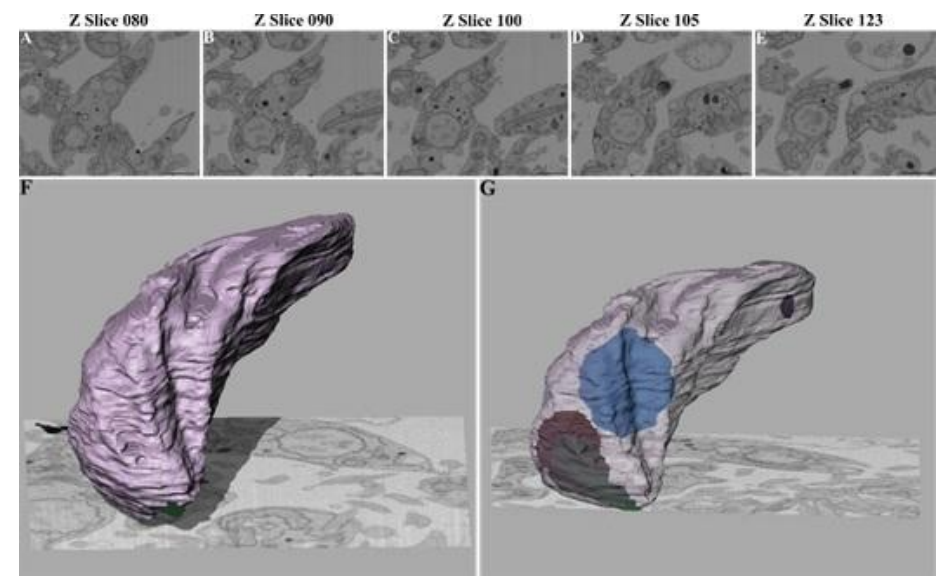

Figure 1: 3D reconstruction of the whole volume of promastigote of L. amazonensis by serial section. (A-D) Obtainment of serial images from $20 \mathrm{~nm}$ - thick serial sections. (E) 3D model showing the plasma membrane (lightpink). (F) 3D model showing the cell nucleus (blue), kinetoplast (red), flagellum (green) and lipids bodies (purple). (G) SEM image. Scale bar: (A-D): $3 \mu \mathrm{m}$; (G): $5 \mu \mathrm{m}$;

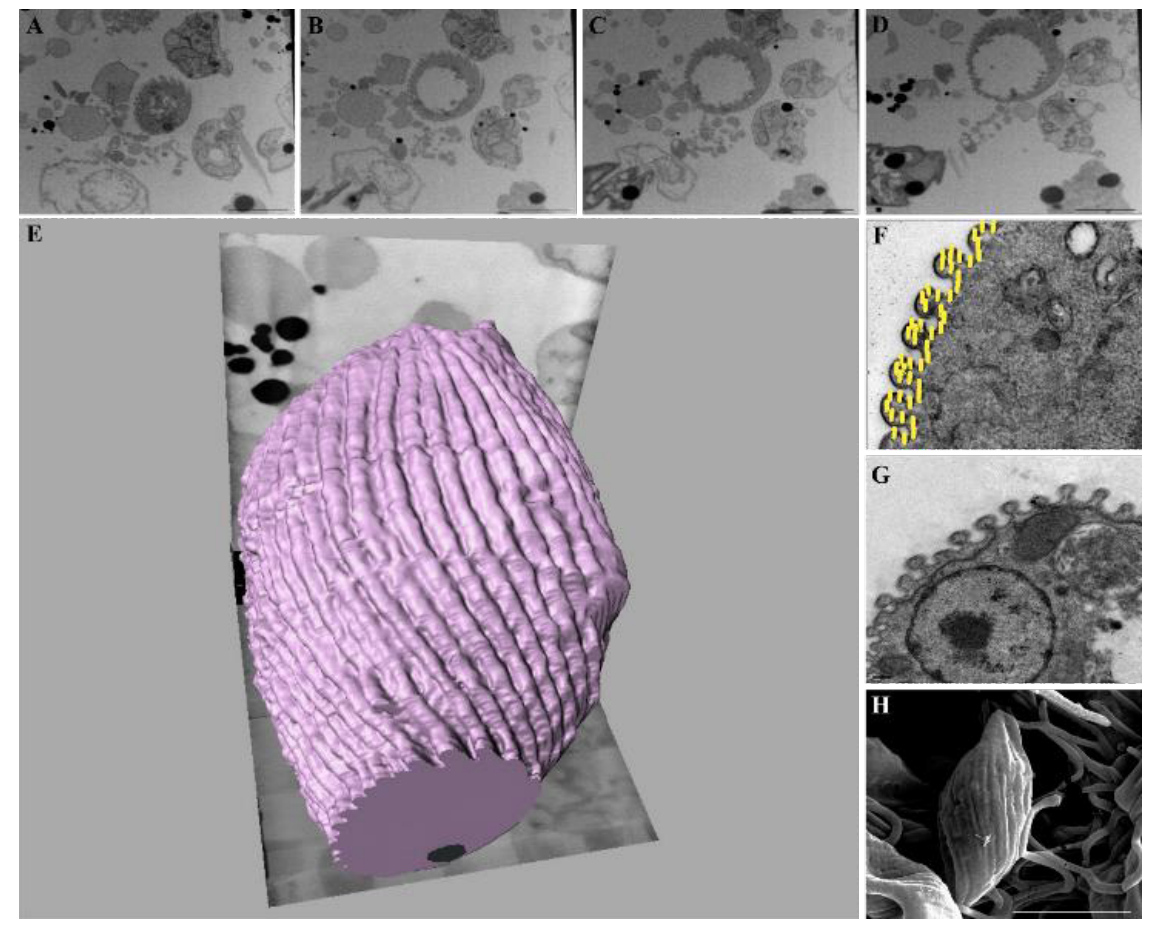

Figure 2: 3D reconstruction of the whole volume of promastigote of L. amazonensis treated with $\mathrm{IC}_{50}$ of ACET-1 by serial section. (A-D) Obtainment of serial images from $20 \mathrm{~nm}$ - thick serial sections. (E) 3D model showing the plasma membrane (lightpink). (F) 3D model showing microtubules (yellow). (G) TEM image. (H) SEM image. Scale bar: (A-D): $4 \mu \mathrm{m} ;(\mathrm{G}): 0,3 \mu \mathrm{m} ;(\mathrm{H}): 3 \mu \mathrm{m}$;

References:

[1] P. David., Journal International of Information Security 69 (2014), p. 10-18.

[2] T. Neeraj., et al. Mini-Reviews in Medicinal Chemistry 18 (2017), p 26-41.

[3] The authors acknowledge funding from the COMCAP-UEM, CNPq, CAPES, PRONEX/Fundação Araucária, FINEP. 